\title{
Metastatic melanoma in Florida, 1996-2010: Racial, demographic, occupational and tumor characteristics, and burden of metástasis
}

\author{
Frederick N. Bebe ${ }^{1}$, Shasa Hu², Tony L. Brown ${ }^{3}$, Orien L. Tulp ${ }^{4}$ \\ ${ }^{1}$ Kentucky State University, College of Agriculture, Food Science and Sustainable Systems Frankfort, KY; USA, ${ }^{2}$ University \\ of Miami, Miller College of Medicine Miami, Florida, USA, ${ }^{3}$ University of Science, Arts and Technology, Monserrat, West \\ Indies - College of Medicine and Graduate School, Denver, CO 80033, USA, ${ }^{4}$ University of Science, Arts and Technology, \\ Monserrat, West Indies - College of Medicine and Graduate School, Denver, CO 80033, USA
}

Corresponding author: Dr. Frederick N. Bebe, E-mail: frederick.bebe@kysu.edu

\begin{abstract}
Background: Recent decades have witnessed an increase in melanoma more than any other cancer, resulting in a 20102014 age-adjusted incidence rate (IR) and mortality rates of 22.3 and 2.7 per 100,000, respectively. Florida's IR is the $2^{\text {nd }}$ highest in the nation and mortality rate has doubled since 1975. Although metastatic melanoma (MM) is less frequent among minorities, it has been increasing steadily over the years. The purpose of this study is to describe the demographic, occupational, tumor characteristics and the burden of metastasis of patients diagnosed with metastatic melanoma in Florida between 1996 and 2010. Materials and Methods: A dataset of 80,349 Non-Hispanic Whites (NHW), African Americans (AA) and Hispanics Whites (HW) stage III and IV metastatic melanoma patients at presentation was obtained from Florida Cancer Data System (FCDS). Demographic information, occupational status and measures related to age at diagnosis, primary site and laterality, histology, grade and staging are reported. Data were analyzed using SAS. Means \pm SD, frequencies, percentages and chi-square tests were employed at $\mathrm{P}<0.05$. Results: Fifteen counties out of 67 accounted for $72 \%$ of all cases; $61 \%$ of the patients were married at time of diagnosis. Forty-eight percent reported having state-sponsored coverage, while $60 \%$ never smoked. Sixty-nine percent were diagnosed with tumors of the trunk, shoulder and hip; laterality was evenly-distributed between left $39 \%$ and right $37 \%$. More AA and HW had tumors that were either moderately or poorly-differentiated. Conclusions: This study confirms well-established race/ethnicity, gender and age disparities in metastatic melanoma diagnosis - majority white and male, and majority of the cases between ages 56 and 71. However, unlike previous studies, laterality was evenly-distributed and majority of AA and HW were diagnosed with moderately or poorly-differentiated tumors.
\end{abstract}

Key words: Occupation; Demography; Tumor characteristics; Metastatic melanoma; Ethnicity

\section{INTRODUCTION}

Recent decades have witnessed an increase in the incidence of melanoma of the skin more than any other cancer, predominantly in adults and resulting in an incidence rate of $3-7 \%$ per year [1-2]. The 2010-2014 age-adjusted incidence and mortality rates were 22.3 and 2.7 per 100,000, respectively [3]. Melanoma of the skin represents $5.2 \%$ of all new cases of cancer in the US. It is estimated that 87,110 new cases of invasive melanoma will be diagnosed in the US in 2017 and about 9,730 will die of the disease. The median age at diagnosis for melanoma of the skin was 64, while that at death was 70 [3]. Overall, melanoma is the sixth most common cancer in men and seventh most common in women; rates are higher for men than for women, and for whites than for all other races combined $[3,4]$.

Florida's incidence rate of melanoma is the $2^{\text {nd }}$ highest in the nation. An estimated 4,928 people were

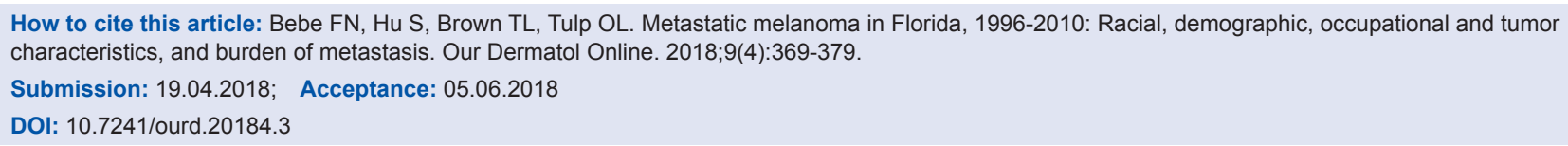


diagnosed with melanoma in 2011 in Florida [5]. Melanoma is responsible for about $75 \%$ of all skin cancer deaths in Florida; about 741 people die of it each year. Since 1975, the death rate of those over 50 in Florida has doubled [5]. Although, melanoma is less frequent among minorities - Hispanics (HIS) and African Americans (AA) - it has been increasing steadily over the years [6]. It is estimated that for people born in 2006, 1 in 53 will be diagnosed with melanoma - nearly 30 times the rate for people born in 1930 [5]. The age adjusted incidence rate from 2006-2010 per 100,000 population for metastatic melanoma was $26 \%$ among whites, $4.5 \%$ for Hispanics and $1 \%$ for AA [7].

It has been suggested that the lower incidence rate of melanoma in HIS and AA compared to NHW could be attributed to the protective effect of darker skin pigmentation, and therefore, perhaps less important role of sun exposure in melanoma development in HIS and AA [8-10]. Melanin in dark skin persons may function as an optical filter that increases the efficiency of DNA repair mechanisms, thus reducing the likelihood of melanoma $[11,12]$. However, the increase of metastatic melanoma over the past few decades among minorities indicates that melanin may only confer partial photoprotection. Therefore other unknown factors may be influential. Elder [10] suggested that acral lentiginous melanoma ALM), the most common subtype in minority populations may be an etiological agent for melanoma other than sun exposure, as it mostly occurs in parts of the body usually protected from the sun and with similar frequencies at different latitudes. The increase in incidence has also been variously attributed to upward class mobility amidst intermittent sun exposure in occupational and recreational settings, and continued ozone depletion $[8,10,13]$. In addition, there have been several reports of a positive correlation between melanoma incidence and socioeconomic status, level of education, inadequate health insurance and sociocultural values $[8,14-17]$. The purpose of this study was to provide an in-depth description of the general demographic, occupational, tumor characteristics and the burden of metastasis of patients diagnosed with metastatic melanoma in Florida between 1996 and 2010.

\section{METHODS}

\section{Study Population and Measurements}

The Florida Cancer Data System (FCDS) database was accessed to identify NHW, AA and HIS patients with metastatic melanoma, specifically those with localized, regional and distant metastasis (stage III and IV) at presentation. A password protected full CD was obtained of cases reported to the FCDS from 1996-2010, including an Acquisition Manual and Data Dictionary for code identification and reference. The study protocol was reviewed and approved by the Florida Department of Health Institutional Review Board and Florida Bureau of Epidemiology. The dataset contained 80,349 patients diagnosed with metastatic melanoma in Florida between 1996 and 2010.

Demographic information included sex, race, marital status, country of birth, state of birth, county of birth, insurance status, history of tobacco use, and occupational status. Measures related to age at diagnosis, primary site and laterality of the tumors, major histology types, and the distribution of grade and stage of the cancers were reported. For descriptive purposes, race/ethnicity was defined as White for all non-Hispanic whites, African American for all who identified as black and Hispanic for all hispanic whites.

\section{Statistical Analysis}

Data were analyzed using the Statistical Analysis Software SAS version 9.4.; SAS Institute, Cary, North Carolina. Descriptive statistics were employed for the whole study data, except where data on specific variables were not otherwise reported. Means and standard deviations were calculated to describe continuous variables, while frequencies and percentages were used to describe categorical variables. Meanwhile chi-square tests were used to test the association between categorical variables, with $\mathrm{p}$-value set at 0.05 for significance.

\section{RESULTS}

\section{Demographic Measures}

Eighty-four percent of the cases were born between 1916 and 1961. Patients were representative of about 50 countries. Of the patients whose country of birth was known, 34\% were born in the United States; $36 \%$ or more of the patients were born or came from nine countries - Argentina, Canada, Columbia, Cuba, Germany Italy, Poland, Puerto Rico and USA (Data not shown). Table 1 reports the frequency distributions of county of birth and occupational distribution data of metastatic melanoma patients. Fifteen counties out of 67 accounted for $72 \%$ of all metastatic melanoma cases 
Table 1. County of birth and occupational distribution of patients diagnosed with metastatic melanoma in Florida 1996-2010

\begin{tabular}{|c|c|c|c|c|c|}
\hline County & Frequency & Percent & Occupation & Frequency & Valid \%§ \\
\hline Palm Beach & 5055 & 10.87 & Transportation \& material moving & 2942 & 9.2 \\
\hline Broward & 4503 & 9.68 & Sales and office & 1370 & 4.4 \\
\hline Miami-Dade & 2922 & 6.28 & Healthcare practitioners \& tech. & 1203 & 3.9 \\
\hline Pinellas & 2868 & 6.17 & Management & 1195 & 3.8 \\
\hline Hillsborough & 2549 & 5.48 & Office and administrative support & 1131 & 3.7 \\
\hline Lee & 1963 & 4.22 & Education training \& library & 1093 & 3.5 \\
\hline Polk & 1937 & 4.17 & Construction and extraction & 785 & 2.5 \\
\hline Orange & 1815 & 3.90 & Business \& financial operations & 679 & 2.2 \\
\hline Brevard & 1709 & 3.67 & Architecture \& engineering & 481 & 1.5 \\
\hline Sarasota & 1495 & 3.21 & Frontline production & 460 & 1.5 \\
\hline Duvall & 1484 & 3.19 & Protective services & 401 & 1.5 \\
\hline Pasco & 1440 & 3.10 & Legal services & 399 & 1.3 \\
\hline Volusia & 1360 & 2.92 & Miscellaneous (un-coded) & 17275 & $21.5^{*}$ \\
\hline Collier & 1220 & 2.62 & Missing (NOS) & 49204 & $61.2^{*}$ \\
\hline Lake & 1059 & 2.28 & & & \\
\hline Total & & 71.76 & & & \\
\hline
\end{tabular}

15 Counties out of 67 account for $72 \%$ of all metastatic melanoma cases diagnosed in FL between 1996 and 2010

*Actual \% of the total patient population of 80,349 . §Percent excluding missing values

diagnosed in FL between 1996 and 2010 (Fig. 1). Out of over 400 occupations, 12 occupations were associated with $39 \%$ (valid \%, i.e. excluding missing values) of the patients. The demographic characteristics of patients diagnosed with metastatic melanoma in Florida from 1996-2010 are shown in Figure 2. Non-Hispanic Whites accounted for $95 \%$ of all metastatic melanoma cases diagnosed, while males formed the majority of the cases at 61 percent, as compared to 39 percent for females. A frequency distribution of the marital status of subjects indicated that $61 \%$ of those with recorded status were married and $27 \%$ either single or divorced.

Primary payer information at diagnosis (Fig. 2) indicated that up to $20 \%$ of the patients were either self-pay, not insured or payer information was not available. However, private insurance and government sponsored programs (Medicare/Medicaid/Tricare etc.) accounted for 32 and 48\%, respectively. Meanwhile, $60 \%$ of patients (excluding missing values) diagnosed with metastatic melanoma had never used cigarettes, while $13 \%$ and $28 \%$ were current and previous users, respectively (Fig. 2).

The time-trend in melanoma diagnosis indicates a steady increase in the incidence rate from 1996-2010, an average increase of approximately $6.7 \%$ or approximately $9.8 \%, 5.7 \%$ and $4.8 \%$ every 5 years consecutively (1996-2000; 2001-2005; 2006-2010) (Fig. 2a). An age distribution of the metastatic melanoma cases shows that $55 \%$ were diagnosed between the ages of 56 and 79, 80 percent between 31 and 79, while only $3 \%$ were below the age of 30 (Fig. 2b).

\section{Tumor Characteristics}

The reporting sources for most of the metastatic melanoma tumors were predominantly hospital (outpatient/inpatient or surgery units) and physician or private practitioner offices (data not shown). The frequency distribution of the primary site of reported tumors shows that the trunk, shoulder, hip, face and neck were the most predominant sites of metastatic melanoma invasion, constituting $90 \%$ of the total (Table 2). Analysis of the dataset indicates that most of the tumors occurred on the right or left of the paired organ of origin or primary $(76 \%)$, or from an unpaired primary site (13\%) - Table 2. Meanwhile, the tumor's resemblance to normal tissue or degree of differentiation of patient tumors (as reported) is described by its grade. Table 2 shows that only about $17 \%$ bore any resemblance to normal tissue, while the rest were either moderately, poorly or totally undifferentiated. At diagnosis, metastatic melanoma is usually classified as either Localized invasive, Regional Spread, or Distant spread. Table 2 indicates that the majority of the patients diagnosed at presentation had tumors $(62 \%)$ that were localized or that had not spread beyond the primary location identified. Only about $11 \%$ had achieved regional or distant spread.

An important criteria in classifying metastatic melanoma is by histologic type. A frequency distribution analysis of the dataset revealed that the major histologic types - nodular melanoma (NM), lentiginous maligna melanoma (LMM), superficial spreading melanoma (SSM) and acral lentiginous melanoma (ALM) - accounted for at least $20 \%$ of the total cases 


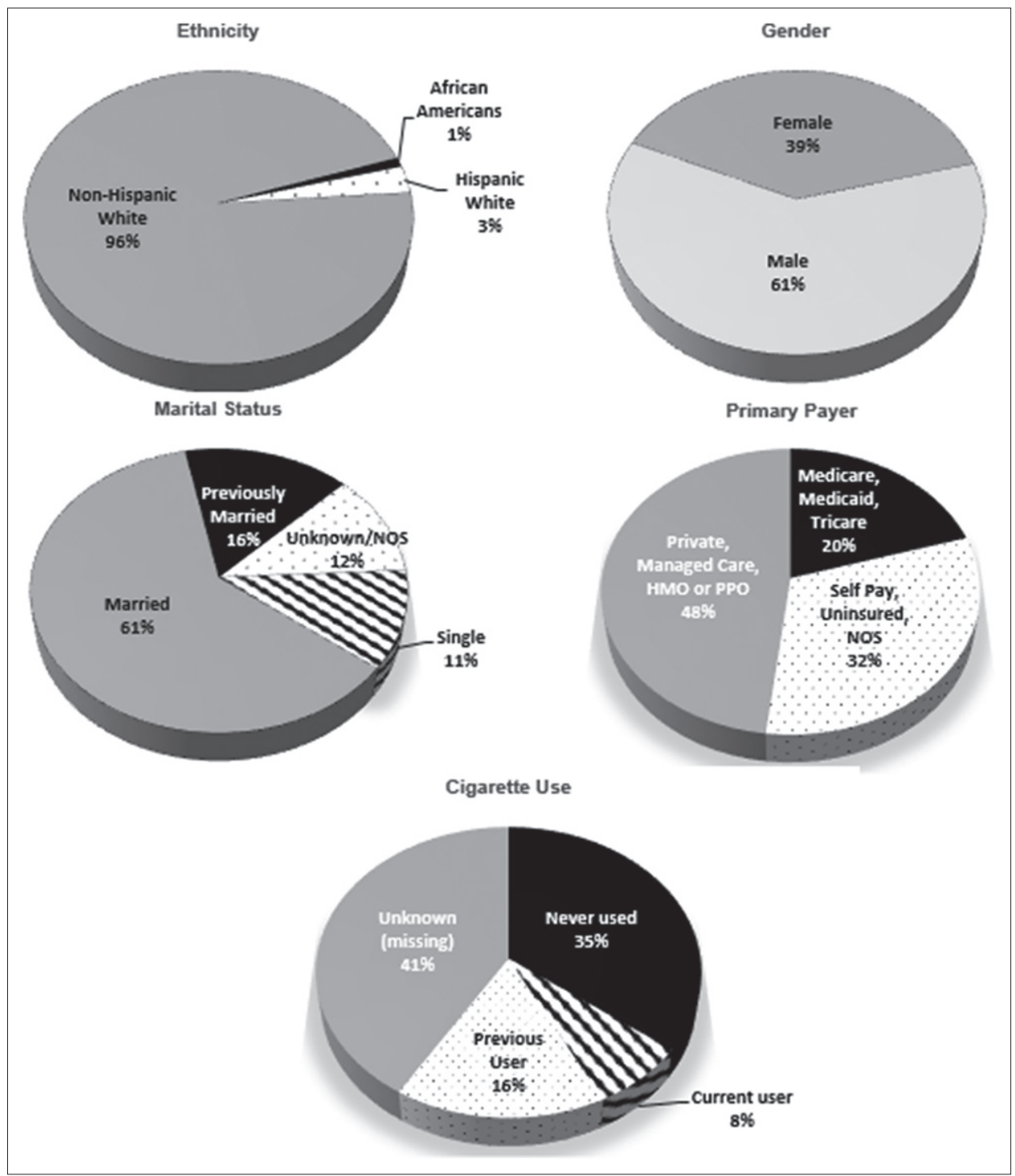

Figure 1: Demographic characteristics of patients diagnosed with Metastatic Melanoma in Florida 1996-2010.

specifically designated, with another $37 \%$ receiving the general designation of malignant melanoma (Table 3). Meanwhile, when distributed by gender, males dominated in each major histologic type.

Table 4 is a cross table of gender, grade and age across race categories. In both male and female categories, NHW dominated the representation reporting more than $95 \%$ in each category. Results of the chi square test indicated that the null hypothesis of no significant association between race and gender was rejected at.05 level of significance $\left(\chi^{2}=66.273, \mathrm{p}=<.001\right)$. Thus, the proportion of males and females was not same across different ethnic categories. In the cross between race and grade, NHS dominated the representation as well, reporting more than $95 \%$ in each category. Results of the Chi square test indicated that the association between race and grade was slightly significant $\left(\chi^{2}=\right.$ $10.485, \mathrm{p}=.045)$.

Summary of results of analysis of variance (ANOVA) F-test for homogeneity of age distribution across races indicated that mean age across races was not comparable as mean age for HIS was less than mean age reported for NHW $(\mathrm{M}=63.17)$ and $\mathrm{AA}(\mathrm{M}=62.281)$. Thus, the null hypothesis of no significant difference in mean age across races must be rejected at.05 level of significance. The mean age distribution was not the same across different racial categories $(\mathrm{p}=<.001)$.

\section{DISCUSSION}

It is well documented that Florida has many advantages for studying melanoma (especially among minorities 


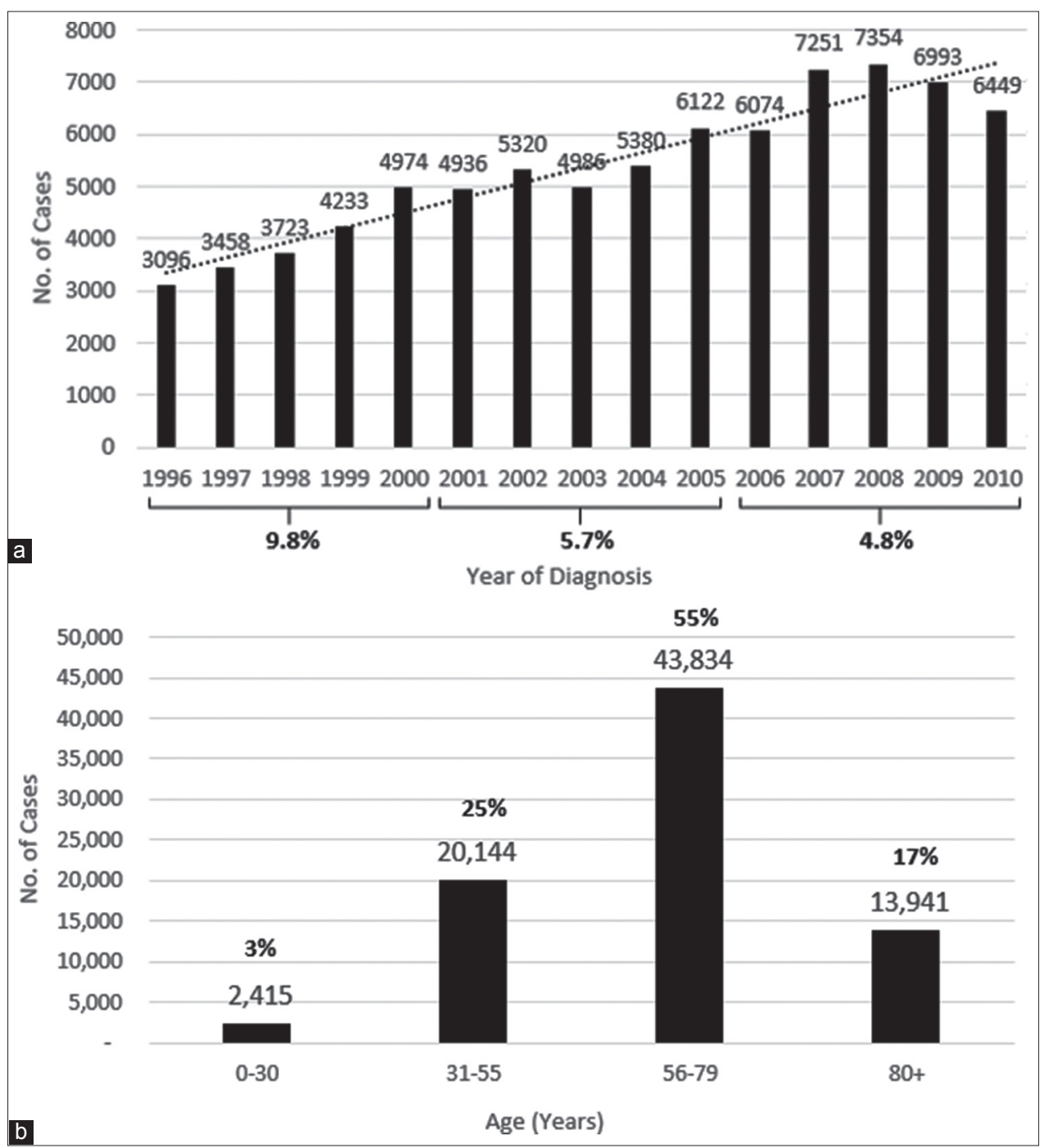

Figure 2: (a) Time Trend in Metastatic Melanoma Diagnosis in Florida 1996-2010. (b) Metastatic Melanoma in Florida - Age at Diagnosis, $1996-2010$.

AA and HIS) in that it is ethnically and racially diverse, with the second highest incidence rate in the US $[4,7,18]$. Diversity in the metastatic melanoma patient population in this study is indicated by the fact that the patients represented 50 countries (including the US), and distributed among all the counties in Florida. However, fifteen Florida counties accounted for $72 \%$ of all metastatic melanoma cases diagnosed - the first 5 being Palm Beach, Broward, Miami-Dade, Pinellas and Hillsborough, almost all of which are located on the southern west and east coasts (Fig. 1).

The incidence rate for melanoma as a whole has been reported to be $2.8 \%$ and $3-7 \%$ per year for Florida and the US, respectively $[3,4,17]$. The latest SEER Stat Fact Sheets for Melanoma 2016, report an increase of $1.4 \%$ each year for the last 10 years [3]; the age adjusted incidence rate for malignant melanoma has been shown to be consistently higher for males than for females, irrespective of race $[3,5,9]$; and for whites than for all minority populations combined. In addition, from 2009 to 2013 , melanoma has been frequently diagnosed among people between the ages of 55 and 64, with a median age of 63 [3]. However, summary data in this study revealed that stage 3 and 4 metastatic melanoma diagnosis in Florida had been increasing yearly by an average of $6.7 \%$ between 1996 and 2010 . A very large majority were NHW (95\%); HIS and AA were $3 \%$ and $1 \%$ respectively, and $55 \%$ of all cases diagnosed were between the ages of 56 and 79 , while $80 \%$ were between the ages of 31 and 79. This study confirms SEER report of consistently higher incidence for males than for females $-60.5 \%$ and $39.3 \%$, respectively [3]. Similarly, when patients with metastatic melanoma in situ and node negative plus or minus ulceration (stage 1 and 2) were excluded in a comparison of gender and race, or 


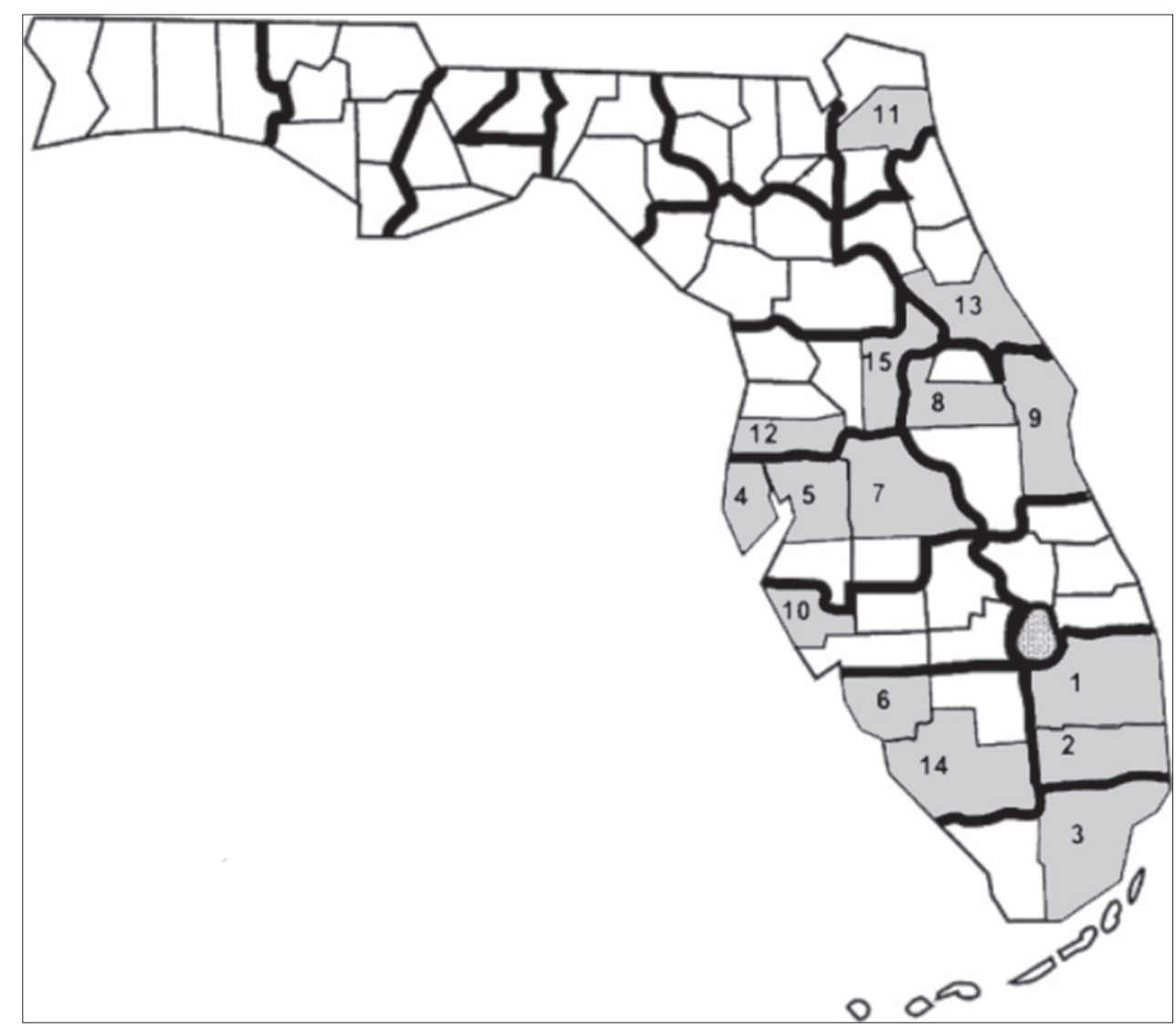

Figure 3: Counties with Highest IR of Metastatic Melanoma (See Table 1).

age and race, the proportion of males and females and the mean age distribution were not the same across race categories $\left(\chi^{2}=66.3, \mathrm{p}=<.001\right.$ and $\mathrm{F}=42.8$, $\mathrm{p}=<.001$, respectively).

Several studies have suggested that patients without medical insurance or those with Medicare/Medicaid are more likely to present with late-stage cancer (including melanoma) than those with private or managed care insurance [19-21], and that irrespective of health insurance racial minorities have an increased risk of diagnosis at late stage $[20,21]$. Halpern et al., reported late stage melanoma odds ratio of $2.3(2.1-2.5)$ and 3.3 (3.0-3.6) for uninsured patients and Medicaidinsured patients respectively, compared to the privately insured [21]. Although this paper does not report on the effect of insurance status on ethnicity, a frequency distribution of primary payer shows that the majority of patients (48\%) had government sponsored coverage (Medicare, Medicaid, Tricare), compared to private coverage (32\%) and self-pay/uninsured (20\%).

The association of marital status with metastatic disease and survival has been reported in a few melanoma studies, with unmarried patients at significantly higher risk than married patients. While controlling for a number of variables, Reyes et al. reported that older widowed patients were likely to be diagnosed at late stage and at greater risk of death than older married patients [22]. Similarly, McLaughlin and colleagues after adjusting for a series of factors indicated that unmarried patients had a higher risk of late stage diagnosis of cutaneous melanoma, with men having a $50 \%$ increased risk than women [23]. This study shows that for those metastatic melanoma patients diagnosed in Florida between 1996 and 2010 and whose marital status was reported, $61 \%$ of them were married at time of diagnosis, while only $11 \%$ were unmarried.

The occupational distribution of patients diagnosed with metastatic melanoma was varied. It was based on the 2010 Census of Occupation Codes and defined as the type of job patients were engaged in for most of their working life. There was an almost even distribution between outdoor (transportation and material moving, construction and extraction, architecture and engineering, frontline production protective services) and indoor reporting occupations (sales and office, healthcare practitioners and technicians, management, office and administrative 
Table 2: Primary site, laterality, grade and stage distribution of tumors of patients diagnosed with metastatic melanoma in Florida, 1996-2010

\begin{tabular}{llcc}
\hline Site Code & Description & Frequency & Percent \\
\hline C443 & Skin of face & 11200 & 13.9 \\
C444 & Skin of scalp and neck & 6179 & 7.7 \\
C445 & Skin of trunk & 23609 & 29.4 \\
C446 & Skin of upper limb and shoulder & 19639 & 24.4 \\
C447 & Skin of upper limb and hip & 12090 & 7632 \\
& Other plus NOS & Frequency & Percent \\
\hline Laterality Code & Description & 10712 & 13.3 \\
\hline 0 & Not a paired site & 29654 & 36.9 \\
1 & Right: Origin of primary & 31265 & 38.9 \\
2 & Left: Origin of primary & 8718 & 10.8 \\
\hline Grade & Other & Frequency* & Percent* \\
\hline 1 & Description & 134 & 16.83 \\
2 & Well differentiated & 168 & 21.11 \\
3 & Moderately differentiated & 346 & 43.47 \\
4 & Poorly differentiated & 148 & 18.59 \\
\hline Stage of Tumor & Undifferentiated & Frequency & Percent \\
\hline Localized & & 49728 & 61.9 \\
Regional & & 4097 & 5.1 \\
Distant & & 1950 & 24576 \\
Unknown (missing) & & 245 & 30.6 \\
\hline SNOS & & &
\end{tabular}

§NOS=Not otherwise stated; *Excludes undetermined or missing values

Table 3: Tumor histology of patients diagnosed with metastatic melanoma in Florida, 1996-2010

\begin{tabular}{llcccccc} 
Type & Description & Frequency & $\%$ & Male & $\%$ & Female & $\%$ \\
\hline 8720 & Malignant Melanoma* & 29299 & 36.5 & 17679 & 60.3 & 11620 & 39.7 \\
8721 & Nodular Melanoma & 3707 & 4.6 & 2392 & 64.5 & 1315 & 35.5 \\
8742 & Lentigo Maligna Melanoma & 1968 & 2.5 & 1295 & 65.8 & 673 & 34.2 \\
8743 & Superficial Spreading M. & 8497 & 10.8 & 4919 & 57.9 & 3578 & 42.1 \\
8744 & Acral Lentiginous M. & 533 & 0.7 & 280 & 52.5 & 253 & 47.5 \\
8745 & Desmoplastic Melanoma & 804 & 1.0 & 585 & 72.8 & 219 \\
& Other/NOS & 35541 & 44.2 & & & & \\
\hline
\end{tabular}

${ }^{*}$ General description

support, education training and library business and financial operations, legal professions) in this study. However, with the exception of transportation and material moving, and construction and extraction, indoor occupations reported patients made up the greatest percentage of those diagnosed with metastatic melanoma. Indeed, Rigel reported greater association of melanoma incidence with indoor workers and those with higher education occupations [24], while Lee and Strickland found that clerks and salesmen had greater rates than skilled manual workers [25]. Similarly, in a study of British and Swedish cancer registries Vagaro et al. reported many high level education occupations with highest associated melanoma risk such as airline pilots, accountants, dentists, finance and insurance brokers. Outdoor workers may have an altered melanoma risk because of ultra violet exposure resulting in an inverse association of high occupational sun exposure with melanoma [26].
An important adverse effect variable or risk factor for a variety of malignancies is tobacco use. But results of studies evaluating the association of tobacco smoking and melanoma have been mixed and far from being causal. Danish and Swedish studies on the association of melanoma and smoking, alcohol and other factors have indicated that the risk of metastatic melanoma was not influenced by smoking $[27,28]$. On the other hand, Freedman et al. and Odenbro et al. reported current smokers, smoking for long durations or previous smokers had a reduced risk for metastatic melanoma as compared to those who never smoked, and that the mechanism for such an inverse associated is yet to be investigated $[29,30]$. On the contrary, smokers have been reported to having greater odds of presenting with late-stage disease [31], with smoking shown to facilitate the spread of metastasis as smokers or more ex-smokers than life-long non-smokers initially presented for melanoma treatment with established metastasis [32]. Although the association between cigarette use and 
www.odermatol.com

Table 4: Gender, grade and age across race categories for patients diagnosed with metastatic melanoma in Florida, $1996-2010$

\begin{tabular}{|c|c|c|c|c|c|c|c|}
\hline \multirow[t]{2}{*}{ Race } & \multicolumn{2}{|c|}{ Sex } & \multirow[t]{2}{*}{ Total } & \multirow[t]{2}{*}{$\left(\chi^{2}\right)$} & \multirow[t]{2}{*}{ P-value } & & \\
\hline & Male & Female & & & & & \\
\hline \multirow[t]{2}{*}{ NHW } & 27300 & 17393 & 44693 & 66.273 & $<.001$ & & \\
\hline & (96.64) & (95.26) & & & & & \\
\hline \multirow[t]{2}{*}{ AA } & 120 & 154 & 274 & & & & \\
\hline & $(0.42)$ & $(0.84)$ & & & & & \\
\hline \multirow[t]{2}{*}{ HIS } & 828 & 711 & 1539 & & & & \\
\hline & (2.93) & (3.89) & & & & & \\
\hline Total & 28248 & 18258 & 46506 & & & & \\
\hline \multirow[t]{2}{*}{ Race } & \multicolumn{4}{|c|}{ Grade } & & & \\
\hline & 1 & 2 & 3 & 4 & Total & $\left(\chi^{2}\right)$ & P-value \\
\hline \multirow[t]{2}{*}{ NHW } & 131 & 158 & 329 & 142 & 760 & 10.49 & 0.045 \\
\hline & (97.76) & (94.05) & (95.09) & (95.95) & & & \\
\hline \multirow[t]{2}{*}{ AA } & 0 & 0 & 8 & 1 & 9 & & \\
\hline & $(0.0)$ & $(0.0)$ & (2.31) & $(0.68)$ & & & \\
\hline \multirow[t]{2}{*}{ HIS } & 3 & 10 & 9 & 5 & 27 & & \\
\hline & (2.24) & (5.95) & $(2.60)$ & (3.38) & & & \\
\hline Total & 134 & 168 & 346 & 148 & 796 & & \\
\hline Race & $\mathbf{N}$ & Mean Age & SD & $F$ & P-value & & \\
\hline $\mathrm{NHW}$ & 44693 & 63.1724 & 16.52542 & 42.78 & $<.001$ & & \\
\hline $\mathrm{AA}$ & 274 & 62.2810 & 17.08751 & & & & \\
\hline HIS & 1539 & 59.2144 & 17.43852 & & & & \\
\hline
\end{tabular}

Values in parenthesis are percentage to the column total

melanoma was not evaluated in the present study, it is clear that the majority of patients diagnosed with metastatic melanoma had never smoked $(60 \%)$ as compared to current or previous smokers (40\%), at time of diagnosis.

It has often been reported that the anatomical distribution of melanoma is different between Whites and minority populations, with Whites developing more of their lesions on sun-exposed surfaces and African Americans and Hispanics predominantly on sun-protected acral sites [33-39]. Acral lentiginous melanoma incidence in African Americans has been estimated to be $60 \%$ to $70 \%[37,40,41]$, compared to approximately $5 \%$ in Whites in whom superficial spreading melanoma predominates [42]. Although some studies have shown that the most common histologic types of metastatic melanoma among all racial groups is SSM or LMM, this study reported (in descending order) that NM, LMM, SSM and ALM were the most important histologic types. However, a direct comparison may not be possible because of the overall low incidence rate of melanoma among minorities; as ALM has been found to be similar or with equal frequency between whites and minority populations in some studies $[43,44]$. The distribution of metastatic melanoma primary site in this study clearly shows that $69 \%$ of metastatic melanoma patients were diagnosed with tumors of the trunk, shoulder and hip, all sunprotected sites consistent with a potential diagnosis of
ALM. However, of the $20 \%$ of patients whose histologic types were positively identified, less than $1 \%$ were classified as ALM.

Laterality describes the side of a paired organ, or side of the body on which the reportable tumor originated and is applicable to the primary site only (44). There has been a dearth of studies on the laterality of metastatic melanoma and probably none comparing ethnic groups. This study of metastatic melanoma patients suggests an almost even distribution of laterality diagnosis between left $39 \%$ and right $37 \%$ - a difference of only $2 \%$. However, two multicenter or country studies of cutaneous melanoma laterality reported consistently higher left to right ratios greater than 1 with no significant differences by sex or age group [45] or left to right ratios greater than 1 for clinical characteristics and a higher left side frequency of about $15 \%$ [46]. It is thought that asymmetric melanocytic distribution, differences in sun exposure and embryonic developmental characteristics to a lesser extent, instead of chance are likely explanations for the observed leftsided excess of invasive cutaneous melanoma [45,46].

Advanced stage melanoma at presentation (stage III and IV) in association with poor survival rates among African Americans and Hispanics compared to Whites has been the subject of a number of studies [3-6,8,9,18,36,47-50]. Even when adjusted for site of primary, histologic type and other variables, 
African Americans and Hispanics were still more likely than White to be diagnosed with late stage disease: $32 \%$ vs $13 \%$ [34] or $14 \%$ vs $4 \%$ [52]. The present study shows a weak association between race and grade $\left(X^{2}=10.5\right.$, $\mathrm{p}=.048)$. In addition, more AA and HIS had tumors that were either moderately or poorly differentiated, thus placing them at regional or distant metastatic stage at diagnosis. The weak level of significance may be due to the low incidence rate in minority populations and the number of patients with reported tumor grade at diagnosis.

This study draws its strength not only from the availability of a large dataset for studying metastatic melanoma, but also from the many advantages Florida has in that it is ethnically and racially diverse, with the second highest incidence rate in the US $[9,15,18]$. This diversity in the metastatic melanoma patient population in this study is indicated by the fact that the patients represented 50 countries and distributed among all the counties in Florida.

However, a number of limitations are worth noting. The incidence rate for AA and HIS patients $5 \%$ and $1 \%$ respectively), was too low to perform an in-depth analysis and may have significantly reduced the statistical power. Complete records were not available for many patients. Patients with not otherwise stated (NOS) or missing values were excluded from some analysis. Excluding patients with missing values may introduce bias and further reduced the power of the study. Classification of metastatic melanoma as NOS histologically seems to be a common problem with registry data. The weak level of significance between race and grade may be due to the low incidence rate in $\mathrm{AA}$ and HIS, and the number of patients with reported tumor grade - an important limitation in this study.

\section{CONCLUSION}

The focus of this study on metastatic melanoma has not only confirmed existing data but revealed a number of points that need to be emphasized: 15 Florida counties out of 67 accounted for $72 \%$ of all metastatic melanoma patients, the majority of whom reported having government sponsored insurance coverage and mostly sustained by outdoor occupations, while over a third had been current or previous smokers. Sixtynine percent of patients were diagnosed with tumors of the trunk, shoulder and hip, all sun-protected sites consistent with a potential diagnosis of ALM. There was a slightly significant association between race and grade with more AA and HIS having tumors that were either moderately or poorly differentiated, thus placing them at regional or distant metastatic stage at diagnosis. This study revealed that metastatic melanoma diagnosis in Florida had been increasing yearly by an average of $6.7 \%$ between 1996 and 2010 and that unmarried patients had a higher risk of late-stage diagnosis than married patients. Given that Florida has the second highest population aged 65 and over in the US, the implications for metastatic melanoma prognosis and survival are yet to be studied. More so, this study suggests an almost even distribution of laterality diagnosis between left $39 \%$ and right $37 \%$ and confirms the well-established race, gender and age disparity in metastatic melanoma diagnosis - majority white and male, and majority of the cases between 56 and 71 years of age.

More studies are needed on tumor histology and in the identification of laterality, with comparison among ethnic groups. There has been a dearth of studies on the laterality of metastatic melanoma and probably none comparing ethnic groups. This study shows clearly that Florida should place more emphasis and resources on prevention and management of metastatic melanoma, especially in those areas and populations most affected.

\section{ACKNOWLEDGEMENTS}

"The Florida Cancer Incidence Data" used in this report were collected by the Florida Cancer Data System (FCDS), the statewide cancer registry funded by the Florida Department of Health (DOH) and the Centers for Disease Control and Prevention's National Program of Cancer Registries (CDC-NPCR). The views expressed herein are solely those of the author(s) and not necessarily reflect those of the DOH or CDCNPCR. We thank Dr. Fisher for statistical help.

\section{REFERENCES}

1. Lipsker DM, Hedelin G, Heid E, Grosshans EM, Cribier BJ. Striking increase of thin melanomas contrasts with stable incidence of thick melanomas. Arch Dermatol. 1999;135:1451-56.

2. Berg P, Lindelof B. Differences in malignant melanoma between children and adolescents. A 35 year epidemiological study. Arch Dermatol 1997;133:295-7.

3. SEER Stat Fact Sheets: Melanoma of the Skin; 2017. http://seer. cancer.gov/statfacts/html/melan.html

4. Howlader N, Noone AM, Krapcho M, Miller D, Bishop K, Kosary CL, Yu M, Ruhl J, Tatalovich Z, Mariotto A, Lewis DR, Chen HS, Feuer EJ, Cronin KA (eds). SEER Cancer Statistics Review, 1975-2014, National Cancer Institute. Bethesda, MD, http://seer. cancer.gov/csr/1975_2014/, based on November 2016 SEER data 
submission, posted to the SEER web site, April 2017.

5. National Cancer Institute and Centers for Disease Control and Prevention. State Cancer Profiles. U.S. state-level, U.S. historical state-level mortality by age, U.S. county-level, and Florida countylevel mortality data queries. Mortality data based on the National: 2009; http://statecancerprofiles.cancer.gov/.

6. Hu S, Parmet Y, Allen G, Parker D F, Ma F, Rouhani P, Kirsner R S. Disparity in Melanoma. Arch Dermatol. 2009;145:1369-74.

7. American Cancer Society. Cancer Facts and Figures Atlanta, GA 2017.

8. Rouhani P, Hu S, Kirsner RS. Melanoma in Hispanic and Black Americans. Cancer Control. 2008;15:248-53.

9. Crest RD, Holly EA. Incidence of cutaneous melanoma among non-Hispanic Whites, Hispanics, Asians and Blacks: an analysis of the California Cancer Registry data, 1988-1993. Cancer Causes Control 1997;8:246-52.

10. Elder EE. Skin Cancer. Melanoma and other specific non-melanoma skin cancers. Cancer. 1995;75:245-56.

11. Armstong B, Kricker A. How much melanoma is caused by sun exposure? Melanoma Res. 1993;3:395-401.

12. Tadokoro T, Kobayashi N, Zmudzka BZ, Ito S, Wakamatsu K, Yamaguchi $\mathrm{Y}$, et al. UV-induced DNA damage and melanin content in human skin differing in racial/ethnic origin. FASEB J. 2003;17:1177-9.

13. Freeman HP. Poverty, culture and social injustice: determinants of cancer disparities. CA Cancer J Clin. 2004;54: 72-7.

14. Harrison RA, Haque AU, Roseman JM, Soong SJ. Socioeconomic characteristics and melanoma incidence. Ann Epidemiol. 1998;8:327-33.

15. Lee PY, Silverman MK, Rigel DS, Vossaert KA, Kopf AW, Bart RS, et al. Level of education and the risk of malignant melanoma. J Am Acad Dermatol. 1992;26:59-63.

16. Gallagher RP, Elwood JM, Threlfall WJ, Spinelli JJ, Fincham S, Hill GB. Socio-economic status, sunlight exposure, and risk of malignant melanoma: the Western Canadian Melanoma Study. J Natl Cancer Inst. 1987;79:647-52.

17. Rouhani P, Pinheiro PS, Sherman R, Arheart K, Fleming LE, MacKinnon J, et al. Increasing Rates of Melanoma Among Nonwhites in Florida Compared With the United States. Arch. Dermatol. 2010;146:741-6

18. Roetzheim RG, Pal N, Voti L, Ayanian JZ, Schwabe A and Krischer JP. Effects of health insurance and race on early detection of cancer. J Natl Cancer Inst. 1999;91:1409-15.

19. Halpern MT, Ward EM, Pavluck AL, Schrag NM, Bian J, Chen AY. Association of insurance status and ethnicity with cancer stage at diagnosis for 12 cancer sites: A retrospective analysis. Lancet Oncol. 2008;9: 222-31.

20. Ward EM, Fedewa SA, Cokkinides V, Virgo K. The association of insurance and stage of diagnosis among patients aged 55 to 74 years in the national cancer data base. Cancer J. 2010;16:614-62.

21. Reyes-Ortiz CA, Freeman JL, Kuo YF, Goodwin JS. The influence of marital status on stage at diagnosis and survival of older persons with melanoma. J Gerontol. 2007; 62A:892-8.

22. McLaughlin JM, Fisher JL, Paskett ED. Marital status and stage at diagnosis of cutaneous melanoma: Results from the Surveillance Epidemiology and End Results (SEER) program, 1973-2006. Cancer. 2011;117:1984-93.

23. Rigel DS. Epidemiology of melanoma. Semin Cutan Med Surg. 2010;29:204-9.

24. Lee JAH and Strickland D. Malignant melanoma: Social status and outdoor work. Br J Cancer 1980;41:757-63.

25. Vagaro D, Swedlow AJ, Beral V. Occupation and malignant melanoma: A study based on cancer registration data in England and wales, and in Sweeden. Br J Ind Med. 1990;47:317-24.

26. Osterlind A, Tucker MA, Stone BJ, Jensen OM. The Danish casecontrol study of cutaneous malignant melanoma. IV. No association with nutritional factors, alcohol, smoking or hair dyes. Int. J Cancer.
1988;42:825-8.

27. Westerdahl J, Olsson H, Masback A, Ingvar C, Jonsson N. Risk of malignant melanoma in relation to drug intake, alcohol smoking and hormonal factors. Br J Cancer. 1996;73:1126-31.

28. Freeman DM, Sigurdson A, Doody MM, Rao RW, Linet MS. Risk of melanoma in relation to smoking, alcohol intake, and other factors in a large occupational cohort. Cancer Causes Control. 2003;14:847-57.

29. Odenbro A, Gillgren P, Bellocco R, Boffetta P, Hakansson N, Adami J. The risk of cutaneous melanoma, melanoma in-situ and intraocular malignant melanoma in relation to tobacco use and body mass index. Br J Dermatol. 2007;156:99-105.

30. Van Durme DJ, Ferrante JM, Pal N, Wathington D, Roetzheim RG, Gonzalez EC. Demographic predictors of melanoma stage at diagnosis. Arch Fam Med. 2000;9:606-11.

31. Shaw HM, Milton GW. Smoking and the development of metastasis from malignant melanoma. Int J Cancer. 1981;28:153-6.

32. Reintgen C, Shivers S, Reintgen M, Giuliano R, Reintgen D. The changing face of malignant melanoma. J Surg Oncol. 2010;101:443-6.

33. Eidei E, Torres SM. A new understanding of the epidemiology of melanoma. Expert Rev Anticancer Ther. 2010;10:1811-23.

34. Byrd KM, Wilson DC, Hoyler SS, Peck GL. Advanced presentation of melanoma in African Americans. J Am Acad Dermatol. 2004;50:21-4.

35. Hudson DA, Krige JE. Melanoma in Black South Africans. J Am Coll Surg. 1995;180:65-71.

36. Swan MC, Hudson DA. Malignant melanoma in South Africans of mixed race ancestry: A retrospective analysis. Melanoma Res. 2003;13:415-9.

37. Giraud RM, Rippey E, Rippey JJ. Malignant melanoma of the skin in Black Africans. S Afr Med J. 1975;49: 665-8.

38. Reintgen DS, McCarty KS, Cox E, Seigler H. Malignant melanoma in the American Black. Curr Surg. 1983;40:215-7.

39. Phan A, Touzet S, Dalle S, Ronger-Savle S, Balme B, Thomas L. Acral lentiginous melanoma: A clinicoprognostic study of 126 cases. Br J Dermatol. 2006;155:561-9.

40. Zell JA, Cinar P, Mobasher M, Ziogas A, Meyskens FL Jr, AntonCulver H. Survival of patients with invasive cutaneous melanoma among ethnic groups: The effects of socioeconomic status and treatment. J Clin Oncol. 2008;26:66-75.

41. Stevens NG, Liff JM, Weiss NS. Planter melanoma: Is the incidence of melanoma of the sole of the feet really higher in blacks than whites? Int J Cancer. 1990;45:691-3.

42. Barnhill RL, Mihm MC Jr. The histopathology of cutaneous melanoma. Semin Diagn Pathol. 1993;10:47-75.

43. Ridgeway CA, Hieken TJ, Ronan SG, Kim DK, Das Gupta TK Acral lentiginous melanoma. Arch Surg. 1995;130:88-92.

44. National Cancer Institute: Surveillance Epidemiology and End Results. Multiple Primary and Histology Coding Rules, Program Bethesda, MD 2007; https://seer.cancer.gov/tools/ mphrules/2007_mphrules_manual_08242012.pdf

45. Brewster DH, Horner MJD, Rowan S, Jelfs P, De Vries, E, Pukkala E. Left-sided excess of invasive cutaneous melanoma in six countries. Eur J Cancer. 2007;43:2634-7.

46. Bulliard JL, Ess S, Bordoni A, Konzelmann I, Levi F. Left-sided excess in the literality of cutaneous melanoma. Arch Dermatol. 2008;144:556-8.

47. Hu S, Parker DF, Thomas AG, Kirsner RS. Advanced presentation of melanoma in African Americans: the Miami-Dade County experience. J Am Acad Dermatol. 2004;51:1031-2.

48. Hu S, Soza-Vento RM, Parker DF, Kirsner RS. Comparison of stage at diagnosis of melanoma among Hispanic, black, and white patients in Miami-Dade County, Florida. Arch Dermatol. 2006;142:704-8.

49. Bellows CF, Belafsky C, Fortgang IS, Beech DJ. Melanoma in African Americans: Trends in Biological and Clinical Characteristics over Two Decades. J Surg Oncol. 2001;78:10-6. 
www.odermatol.com

50. Bradford PT. Skin cancer in skin of color. Dermatol Nurs. 2009;21:170-7.

51. Metzger S, Ellwanger U, Stroebel W, Rassner G, Fierlbeck G. Extent and consequences of physician delay in the diagnosis of acral melanoma. Melanoma Res. 1998;8:181-6.

52. Reyes-Ortiz CA, Goodwin JS, Freeman JL. The effect of socioeconomic factors on incidence, stage at diagnosis and survival of cutaneous melanoma. Med Sci Monit. 2005;11:RA163-72.
53. O'Hanlon L. Invasive melanoma on the rise in Californian Hispanics. Lancet Oncol. 2006;7:199.

Copyright by Frederick N. Bebe, et al. This is an open-access article distributed under the terms of the Creative Commons Attribution License,

which permits unrestricted use, distribution, and reproduction in any medium, provided the original author and source are credited.

Source of Support: Nil, Conflict of Interest: None declared. 